\title{
Progeria
}

\section{Case Report with Long-term Studies of Serum Lipids}

\author{
B. G. P. MACNAMARA, K. T. FARN, A. K. MITRA, JUNE K. LLOYD, \\ and AUDREY S. FOSBROOKE \\ From the George Eliot Hospital, Nuneaton, and the Department of Child Health, University of London
}

Macnamara, B. G. P., Farn, K. T., Mitra, A. K., Lloyd, J. K., and Fosbrooke, A. S. (1970). Archives of Disease in Childhood, 45, 553. Progeria: case report with long-term studies of serum lipids. A girl with the typical features of progeria died at the age of 10 years from cardiac failure following repeated myocardial infarctions. Serial studies of the serum lipids were made from the age of 2 years 3 months. Variable hyperlipidaemia, increased $\beta$ - and pre- $\beta$-lipoproteins, and impaired clearing of absorbed dietary fat were shown. A polyunsaturated fat diet, which was started at the age of 2 years 5 months and continued throughout the rest of her life, controlled the hyperlipidaemia and the clearing of fat became normal. Pre- $\beta$-lipoprotein could still, however, be seen occasionally. The dietary regimen did not delay the development of atherosclerosis, the pathogenesis of which, in progeria, may be due to factors other than hyperlipidaemia.

Progeria was first described by Hutchinson in 1886 and named by Hastings Gilford in 1897 . The term means prematurely old. Individuals appear normal at birth and weight gain is usually satisfactory during the first year of life, but thereafter virtually ceases. Growth in height is retarded and rarely exceeds that of a normal 4- or 5-year-old. Intelligence is normal. The appearance has been likened to a 'plucked bird' or very old man because of baldness and lack of subcutaneous fat; the skin is atrophic and often shows brown pigmentation. The nails are atrophic or absent. The eyes are prominent and the nose beaked; the chin recessive and the maxilla hypoplastic. The chest is narrow and the abdomen protrudes. Clinical manifestations of osteoarthritis and arteriosclerosis may appear before the sixth year. The commonest cause of death is myocardial infarction and survival beyond the second decade is rare. The radiological features, which consist of hypoplastic facial bones, delay of cranial suture and fontanelle closure, thin short clavicles, coxa valgus, and progressive acro-osteolysis of the terminal phalanges have been recently reviewed by Margolin and Steinbach (1968), Ozonoff and Clemett (1967), and Macleod (1966).

Received 30 January 1970.
About 45 cases have been reported to date and the literature was reviewed in 1950 by Thomson and Forfar, and in 1964 by Ghosh and Varma. The aetiology is unknown. Disordered pituitary function was suggested originally by Hutchinson and by Gilford but no conclusive evidence of pituitary dysfunction has been demonstrated. Talbot $e t$ al. in 1945 postulated that the defect was due to an inborn error of metabolism. In a more recent report Villee, Nichols, and Talbot (1969) described metabolic studies on two boys with progeria. These children were unresponsive to growth hormone, relatively insulin resistant, and had highly cross-linked collagen. The authors concluded that the disorder was due to mesenchymal dysplasia in which connective tissue cells are unresponsive to growth influences. They speculated that the dysplasia led to structural changes in the arterial walls. Fibroblast cultures obtained from a 9-year-old boy with progeria have been shown to live for only 2 subcultures, in comparison with 20-30 subcultures in age-matched controls (Goldstein, 1969). A genetic component in the aetiology is suggested by the report of two affected sibs whose parents were first cousins (Mostafa and Gabr, 1954), and the report of a further case in the offspring of a consanguineous marriage (Bhakoo, Garg, and Sehgal, 1965). 
A relation between the atherosclerosis and disordered lipid metabolism has been suggested by several workers. Of the 36 cases reviewed by Ghosh and Varma (1964), raised serum cholesterol was reported in 14. Raised $\beta$-lipoprotein levels have been reported in some cases (Keay, Oliver, and Boyd, 1955; Rosenthal et al., 1956), and Keay et al. also found the ratio of cholesterol to phospholipid to be increased. In some patients, however, cholesterol and lipoproteins have been found to be normal (Villee et al., 1969; Kaiman, Lambie, and Metzl, 1969).

This report describes a patient whose day-to-day care from birth to death has been supervised by one of us (K.T.F.), and in whom the finding of abnormalities of the serum lipids resulted in dietary treatment in an attempt to prevent, or at least delay, the onset of atherosclerosis.

\section{Case Report}

The patient, a girl, was the second child of healthy unrelated parents; her brother was also healthy. She was born in September 1958 by breech delivery at 35 weeks' gestation and weighed $2.6 \mathrm{~kg}$.; there had been meconium staining of the liquor, but her condition at birth was satisfactory and she gave no cause for concern until the age of 3 months when puckering of the skin of the legs was first noticed. At 5 months of age she was referred to hospital with a tentative diagnosis of lymphangiectasia: her weight was $5.4 \mathrm{~kg}$. (3rd centile for her age). Over the next 18 months her weight progress slowed, so that at 1 year she weighed only $6 \cdot 2 \mathrm{~kg}$. and at 2 years $7 \cdot 2 \mathrm{~kg}$. (both well below 3rd centile). Her height at 2 years was $75 \mathrm{~cm}$. (also below the 3rd centile) and her appetite was poor but her developmental achievements normal. The typical features of progeria now became obvious (Fig. 1); there were atrophic changes in the skin of the hands, the nails were short, and there was limitation of joint movement. The diagnosis was established by Dr. A. C. Kendall, and she was transferred to the Birmingham Children's Hospital in November 1960, at the age of 2 years 3 months for further studies.

Investigations showed: normal $\mathrm{Hb}$, white blood count, platelets, prothrombin time, erythrocyte sedimentation rate, serum proteins, calcium, and urea. An oral glucose tolerance test was normal and estimation of plasma insulin at a later stage (1966) showed a normal fasting level. Tests of thyroid function showed a normal PBI $\left(4.9 \mu \mathrm{g} . / 100 \mathrm{ml}\right.$.) and a slow but normal uptake of ${ }^{132} \mathrm{I}$ by the thyroid. Urinary 17-ketosteroids, 17-hydroxycorticosteroids, and amino acids were normal. The duodenal juice contained normal concentrations of pancreatic enzymes. A buccal mucosal smear was chromatin positive and lymphocyte culture showed the chromosomes to have a normal female karyotype. An

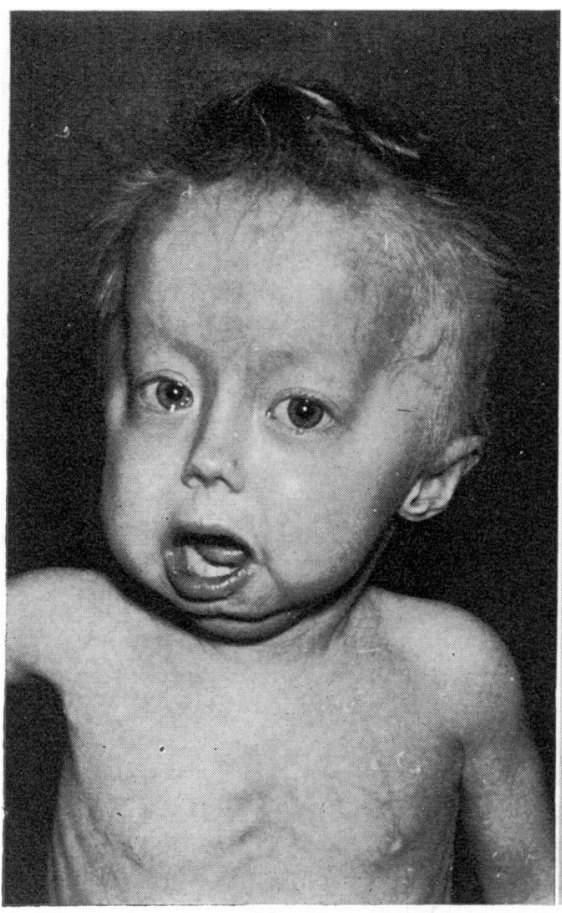

(a)

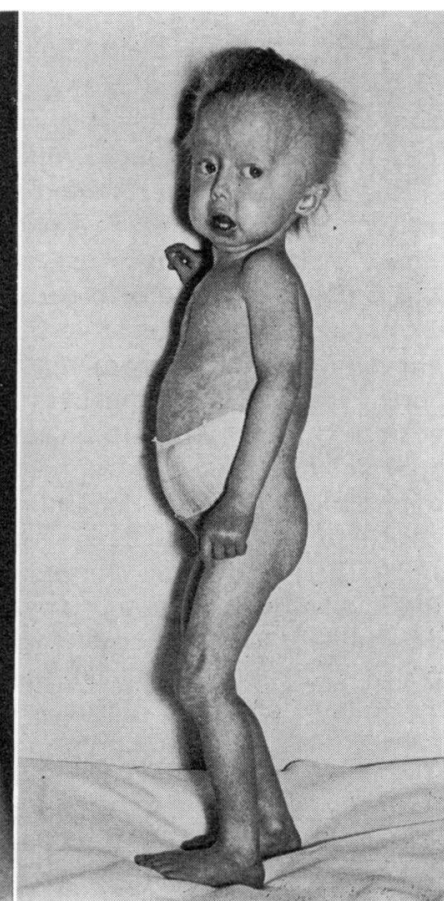

(b)

Fig. 1.-Patient at 2 years of age. 
EEG was normal. Radiological investigations showed a large cranial vault; the terminal phalanges of the toes and hands were hypoplastic; the bone age was within normal limits for the chronological age. The chest $x$-ray showed no cardiomegaly and the initial ECG was normal. Skin biopsy from the forearm showed the epidermis to be moderately hyperkeratotic, but the subcutaneous adipose tissue appeared microscopically normal. No changes were seen in hair follicles, sebaceous glands, or blood vessels (Dr. A. H. Cameron). Muscle biopsy from the right flexor carpi radialis showed that the muscle appeared normal but the axons of some intramuscular nerve bundles were thickened possibly due to degenerative swelling (Dr. A. L. Woolf). Results of investigations of serum lipids are reported in a later section.

Management and progress. Methandienone was given from December 1960 to March 1961 at a dose of $2 \mathrm{mg}$. daily, and from February 1962 to October 1963 at a dose of $0.4 \mathrm{mg}$. daily. On each occasion there was a slight increase in growth rate after starting the drug, but this effect was not maintained. A polyunsaturated fat diet as described by Lloyd and Jukes (1961) was

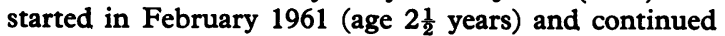
until death in 1969; the effect of this regimen on the serum lipids is described later.
During 1962 and 1963, though growth remained poor, she became increasingly active and entered into the normal activities of children in her home area. Her intelligence was normal and she was accepted into the village school. The provision of a wig greatly helped her social adjustment. By the age of $3 \frac{1}{2}$ years the ECG showed evidence of left ventricular preponderance and this abnormality persisted in subsequent tracings. By the age of 7 she was showing marked osteoarthritic changes with limitation of movement of virtually all joints, and by the age of 8 had begun to have angina on effort. In April 1967, at the age of $8 \frac{1}{2}$ years, she was admitted to the George Eliot Hospital, Nuneaton, with an anterior myocardial infarction. After her discharge she attended Bramcote Hospital School travelling to and from home by taxi. Her intelligence remained normal and she spent her spare time at home reading, writing, and painting.

In September 1967 digoxin was started because of persistent tachycardia. In April 1969 she developed congestive cardiac failure with gross oedema. Temporary improvement was achieved by increasing the dose of digoxin and adding a diuretic. However, relapse soon occurred and she was readmitted in May to the George Eliot Hospital, cyanosed, dyspnoeic, and pop-eyed (Fig. 2). There was gross oedema of the legs and trunk, ascites, and hepatomegaly. Her body was

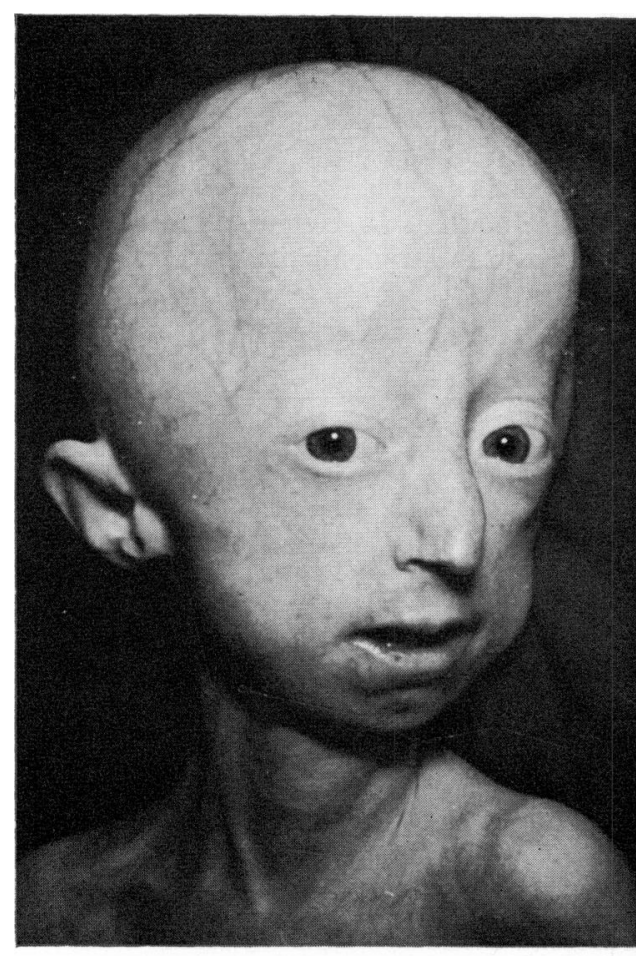

(a)

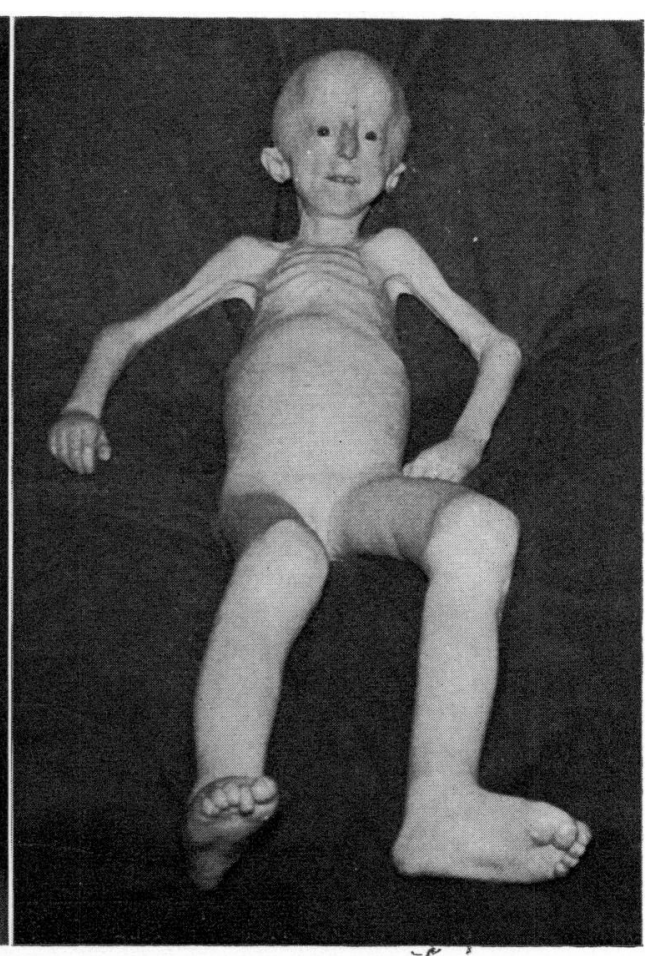

(b)

Fig. 2.-Patient at $10 \frac{1}{2}$ years shortly before death. 
emaciated and she had conspicuous arthritis especially in her knees and hands. Despite intensification of her therapy she died four days after admission at the age of 10 years 9 months.

Necropsy. (A.K.M.) This showed the typical appearances of progeria, with complete absence of hair including eyebrows, receding jaw, beaked nose, thin extremities with lack of skin turgor. The heart was much enlarged mainly due to left ventricular dilatation weight 175 g.). The myocardium showed numerous infarcts, mainly anterior and apical. The left ventricle contained adherent thrombus and the endocardium was thickened. The left coronary artery was of small calibre. Both main branches showed calcification of the wall and insufficiency. There was no obvious recent thrombus in the vessels. The aorta showed yellow plaques in the descending portion, and in the ascending portion a few atheromatous ulcers. The lungs showed congestion and consolidation of the lower lobes due to mild bronchopneumonia. The liver showed a slight nutmeg pattern. The brain showed no abnormality, nor did the adrenals, urogenital system, or the alimentary tract.

\section{Studies of Serum Lipids}

All analyses were made on venous blood. Total lipid was estimated by the method of De la Huerga, Yesinick, and Popper (1953), total cholesterol by the method of Sackett (1925), total light dispersing material by the method of Fosbrooke and Rudd (1966), and non-esterified fatty acids by the method of Dole and Meinertz (1960). Serum lipoproteins were separated by paper electrophoresis according to the method of Salt and Wolff (1957) and ultracentrifugation was carried out by the method of Cornwell et al. (1961). Before ultracentrifugation the serum was subjected to a spin at $10,000 \times g$ for 30 minutes.
The clearing of absorbed dietary fat was investigated by making serial estimations of serum lipids after a breakfast meal containing $2 \cdot 2 \mathrm{~g}$. fat per $\mathrm{kg}$. (either ordinary fat largely of animal origin or corn oil) together with carbohydrate and protein; during the remainder of the test period a fat-free diet was given. Blood for baseline values at the start of these tests was obtained after an overnight fast (at least 12 hours). These investigations were carried out using each type of fat before the introduction of the corn oil diet, and were repeated 1 and 3 years after the start of the diet as indicated in Fig. 3. During the follow-up period the majority of blood samples were obtained about 3 hours after a standardized breakfast.

\section{Results}

Serum total lipid and cholesterol concentrations are shown in Fig. 3. The initial observations made in November 1960 at the age of 2 years 3 months showed normal values though marked fluctuations occurred within a few weeks. In January 1961 serum in the fasting state showed a high total lipid and a marked pre- $\beta$-lipoprotein band on electrophoresis (Fig. 4). At this stage the clearing of dietary fat, both ordinary and corn oil, was abnormal as shown in Fig. 5. For both types of fat, lipaemia was excessive and clearing delayed; corn oil resulted in much greater lipaemia but appeared to be cleared more efficiently. Paper electrophoresis showed marked increases in the $\beta$-lipoprotein fraction (including pre- $\beta$ lipid) after both types of meal; this is an abnormal response, the increase in lipoprotein after a fat-containing meal usually being confined to the chylomicron fraction. Analyses of

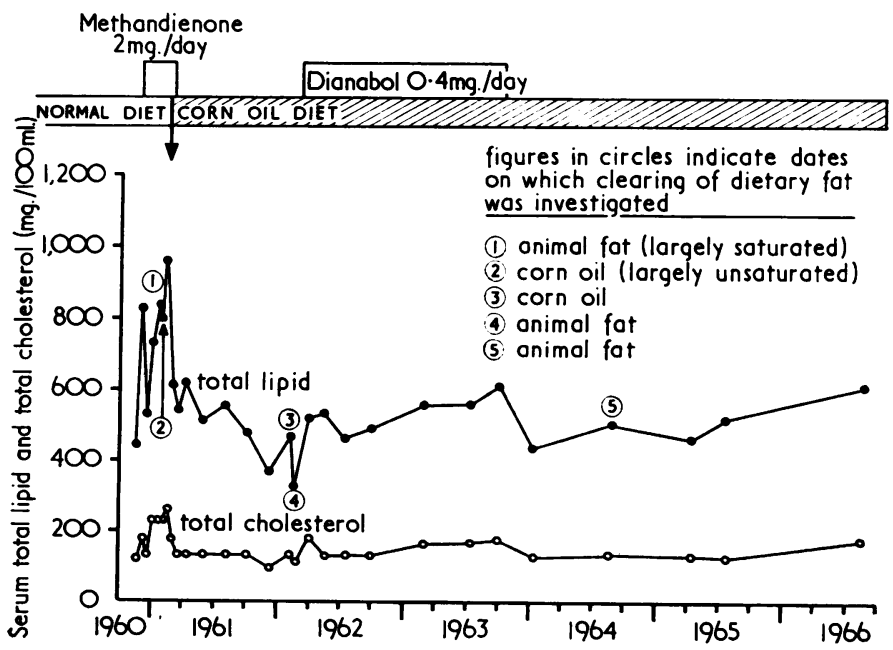

FIG. 3.-Serial studies of serum lipids. Normal ranges for total lipid 470-860 $\mathrm{mg} .1100 \mathrm{ml}$., and total cholesterol 120-230 mg./100 ml. 


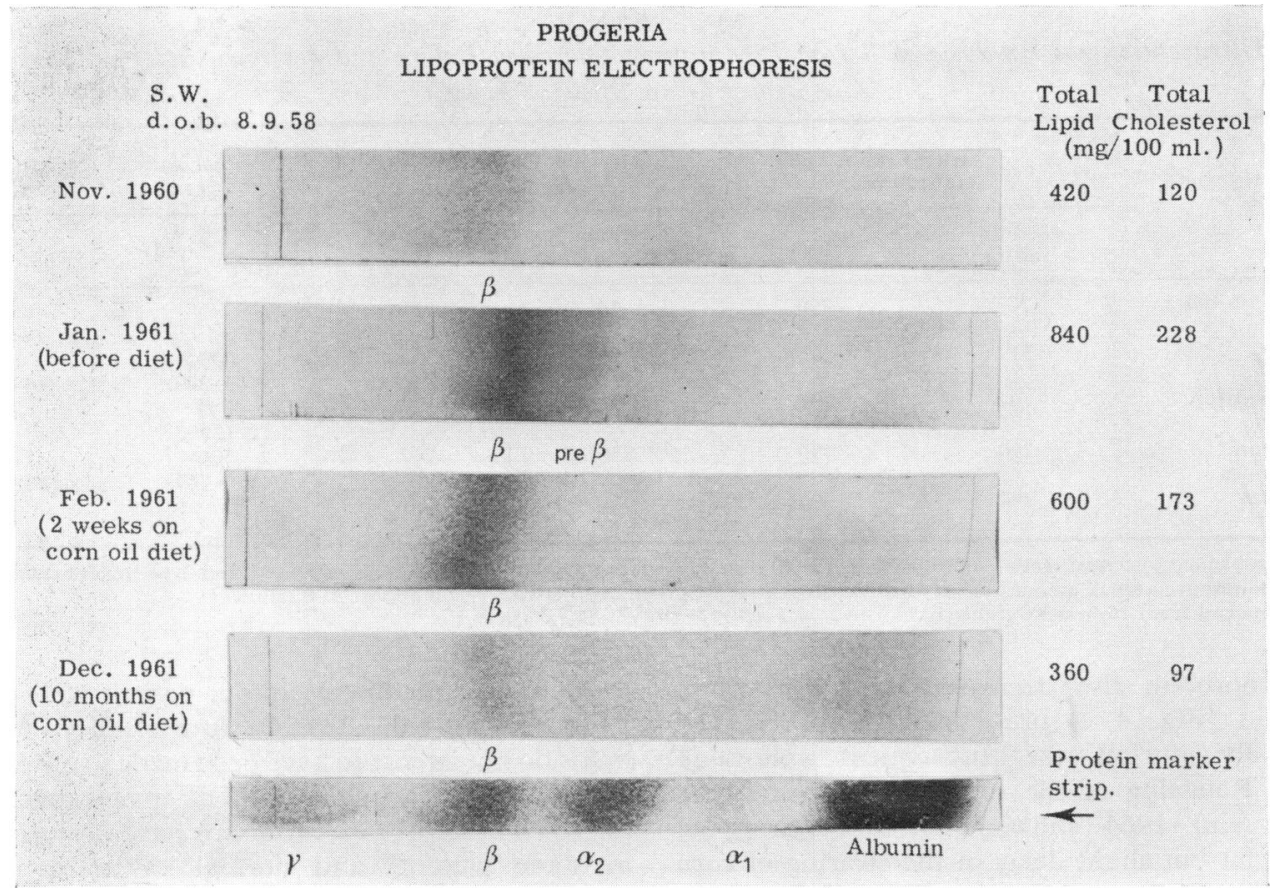

FIG. 4.-Serum lipoprotein electrophoresis.

lipoproteins separated in the ultracentrifuge before and 4 hours after the corn oil meal are given in the Table. In the fasting state concentrations of total lipid and cholesterol were increased in fractions I and II (corresponding to pre- $\beta$-lipoprotein) and in fraction III ( $\beta$-lipoprotein). After the meal further increases in total lipid were observed in fractions I and II and in fraction III, and a decrease in fraction IV ( $\alpha$-lipoprotein).
The fasting plasma non-esterified fatty acid (NEFA) concentration was normal $(0.92 \mathrm{mEq} / \mathrm{l}$.$) ,$ as was the response of plasma NEFA to an oral glucose load.

After the introduction of the corn oil diet in February 1961 total lipid and cholesterol concentrations fell, and, though fluctuation still occurred, the levels remained within normal limits at the times of the tests over the next 6 years (Fig. 3). Though

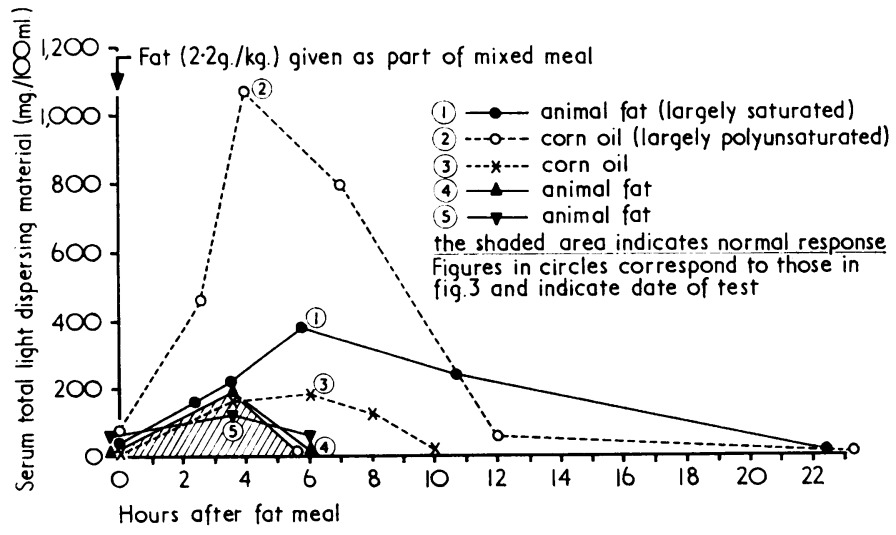

Fig. 5.-Clearing of absorbed dietary fat. 
TABLE

Ultracentrifugal Analysis of Serum Lipoproteins Obtained Before and 4 Hours After a Meal Containing Corn Oil (2.2 g./kg.)

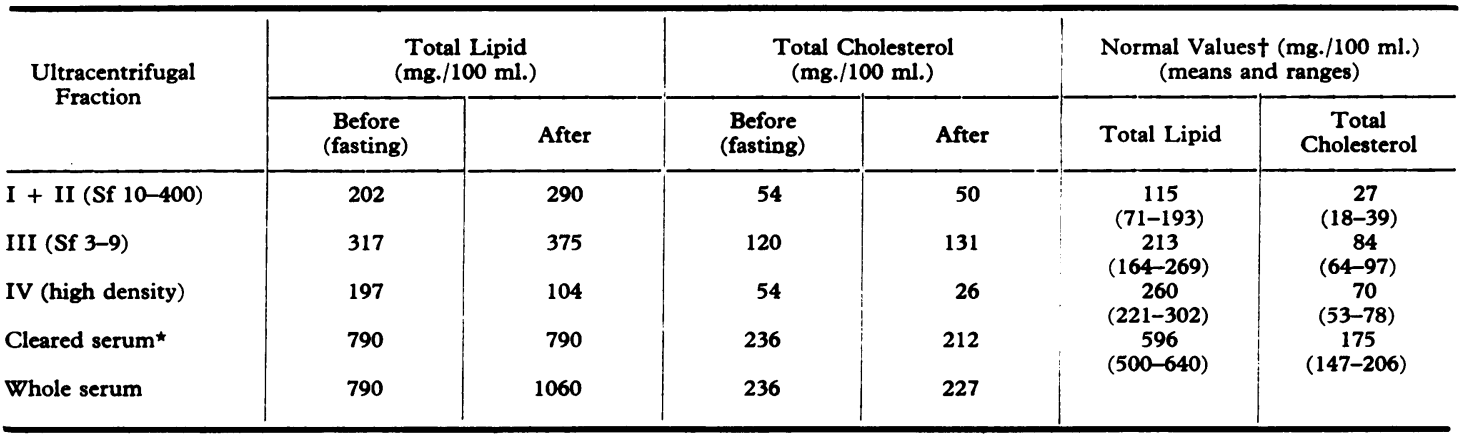

*Serum subjected to centrifugation at $10,000 \times g$ for 30 minutes before ultracentrifugation. This process removes chylomicron material but may also remove a small amount of very low density lipoprotein which otherwise would appear in fractions I + II.

tData obtained from 10 healthy children.

pre- $\beta$-lipoprotein also decreased with the fall in total lipid (Fig. 4) a pre- $\beta$ band was observed occasionally during the subsequent follow-up period. Retesting of the responses to dietary fat in 1962 and 1964 showed normal clearing of ordinary fat but slight delay in the clearing of corn oil (Fig. 5).

\section{Discussion}

The clinical and radiological features (Fig. 6) and the course of the disease in our patient were similar to those reported. Longitudinal studies of serum lipids do not appear to have been made in other cases, and the findings in our patient may explain why raised cholesterol concentrations have been reported in some patients and normal values in others. Our initial investigations showed normal cholesterol and lipoproteins on some occasions, and raised cholesterol with increased $\beta$ - and pre- $\beta$-lipoproteins on others. It was also found that the child's ability

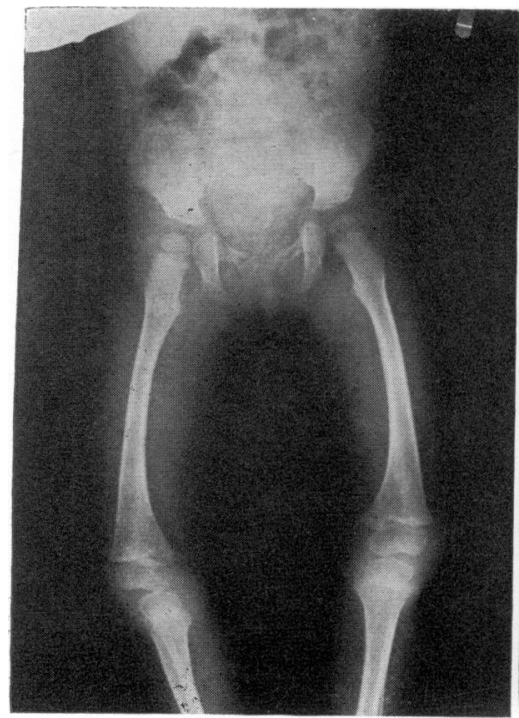

(a)

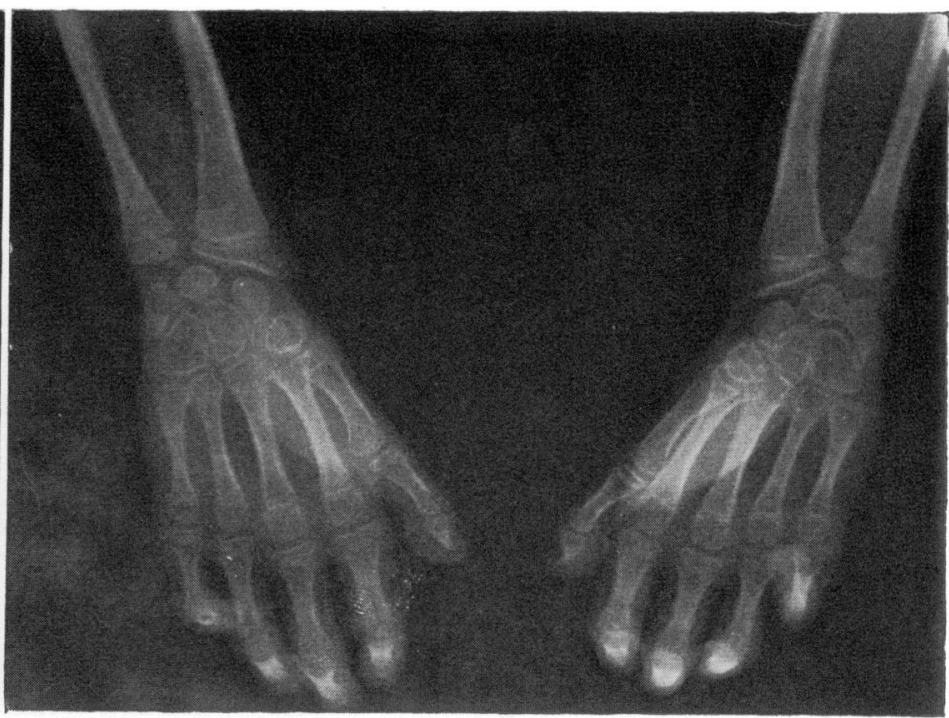

(b)

Fig. 6.-(a) $X$-ray of pelvis and femora of the patient at the age of 2 years showing marked coxa valga. (b) $X$-ray of the patient's hands at the age of 6 years and 9 months showing sclerosis and destruction of terminal phalanges ('acro-osteolysis'). 
to clear dietary fat was impaired, increases in $\beta$ - and pre- $\beta$-lipoprotein occurring after a meal containing fat, and that the response to corn oil (mainly polyunsaturated fat) was different from that after a meal of ordinary fat (largely saturated). Interpretation of the serum lipid data in progeria therefore requires knowledge of the time of sampling in relation to meals and of the composition of the dietary fat. Serial studies should be made before lipids or lipoproteins are reported to be normal; our case would have been recorded as having normal serum lipids had the investigation been limited to the initial samples.

The mechanism of the delayed clearing of absorbed dietary fat in progeria has not been defined, nor has the reason why excess lipid should accumulate in $\beta$ - and pre- $\beta$-lipoproteins. We did not estimate the plasma post-heparin lipolytic activity (lipoprotein lipase), but very low activities have been reported in total lipodystrophy (Fosbrooke and Segall, 1969); in this condition there is also gross deficiency of adipose tissue, and delayed clearing of dietary fat has been observed. The increased lipaemia after a meal containing a considerable amount of polyunsaturated fat can be explained by its more rapid absorption (Fernandes, van de Kamer, and Weijers, 1962), and the increased rate of clearing may result from differences in the rate of hydrolysis of saturated and unsaturated lipids by lipoprotein lipase.

A polyunsaturated fat diet was used in the treatment of our patient for its hypocholesterolaemic effect. At that time we did not fully appreciate the significance of the increase in pre- $\beta$-lipoprotein in so far as this is usually indicative of endogenous hypertriglyceridaemia. The effect of our dietary treatment was to modify the serum lipid pattern so that concentrations of total lipid and cholesterol remained within the normal range throughout the long follow-up period, and the defect in clearing dietary fat was abolished. The improvement in clearing can be attributed to the reduction in fasting serum lipid levels, the rate of clearing of ingested fat being significantly correlated with fasting serum triglyceride concentrations (Nestel, 1964). The serum lipid abnormality was not, however, completely controlled in our patient as pre- $\beta$-lipoprotein could still be shown occasionally, even when total lipid and cholesterol levels were normal. A polyunsaturated fat diet alone is thus not ideal therapy for control of the disorder of lipid metabolism in progeria. The pre- $\beta$-lipoproteinaemia could probably be better controlled by reduction in dietary carbohydrate or by the use of drugs such as clofibrate.
The pathogenesis of the atherosclerosis in progeria is not understood and may well differ from that in other conditions, for example in diabetes mellitus and familial hypercholesterolaemia. Villee et al. (1969) do not consider that disordered lipid metabolism has any primary role in the pathogenesis of the arterial lesions which they suggest are due to structural changes in the wall consequent upon the mesenchymal dysplasia. The failure of the dietary regimen to delay the development of atherosclerosis in our patient, though disappointing, should not be taken as an indication that control of serum lipids in other disorders associated with premature atherosclerosis will be unsuccessful.

We thank Dr. G. W. Chance who continued to see the patient at Birmingham Children's Hospital from 1965 to 1968 , and for giving us details of the serum lipid studies made during that time.

\section{REFERENCES}

Bhakoo, O. N., Garg, S. K., and Sehgal, V. N. (1965). Progeria with unusual ocular manifestions: report of a case with a review of the literature. Indian Pediatrics, 2, 164.

Cornwell, D. G., Kruger, F. A., Hamwi, G. J., and Brown, J. B. (1961). Studies on the characterisation of human serum lipoproteins separated by ultracentrifugation in a density gradient. American fournal of Clinical Nutrition, 9, 24.

De la Huerga, J., Yesinick, C., and Popper, H. (1953). Estimation of total serum lipids by a turbidimetric method. American fournal of Clinical Pathology 23, 1163.

Dole, V. P., and Meinertz, H. (1960). Microdetermination of long-chain fatty acids in plasma and tissues. Fournal of Biological Chemistry, 235, 2595.

Fernandes, J., van de Kamer, J. H., and Weijers, H. A. (1962). Differences in absorption of the various fatty acids studied in children with steatorrhea. Fournal of Clinical Investigation, 41, 488.

Fosbrooke, A. S., and Rudd, B. T. (1966). The determination of particulate fat in serum and its use in clinical studies. Clinica Chimica Acta, 13, 251.

—, and Segall, M. M. (1969). Observations on fat and carbohydrate metabolism in generalized lipodystrophy. Biochemical Fournal, 112, 33P.

Ghosh, S., and Varma, K. P. S. (1964). Progeria: report of a case with review of the literature. Indian Pediatrics, $1,146$.

Gilford, H. (1897). Medico-Chirurgical Transactions, 80, 17.

Goldstein, S. (1969). Lifespan of cultured cells in progeria. Lancet, 1, 424.

Hutchinson, J. (1886). Congenital absence of hair and mammary glands with atrophic condition of the skin and its appendages. Medico-Chirurgical Transactions, 69, 473.

Kaiman, H., Lambie, R. W., and Metzl, K. (1969). Progeria: case description. Clinical Pediatrics, 8, 411.

Keay, A. J., Oliver, M. F., and Boyd, G. S. (1955). Progeria and atherosclerosis. Archives of Disease in Childhood, 30, 410.

Lloyd, J. K., and Jukes, H. R. (1961). Diet rich in unsaturated fat. Lancet, 1, 312.

Lancet, 1, 312.
Macleod, W. (1966). Progeria. British fournal of Radiology, 39, 224.

Margolin, F. R., and Steinbach, H. L. (1968). Progeria: Hutchinson-Gilford syndrome. American fournal of Roentgenology, Radium Therapy, and Nuclear Medicine, 103, 173.

Mostafa, A. H., and Gabr, M. (1954). Heredity in progeria, with follow-up of two affected sisters. Archiec: of Pediatrics, 71, 163.

Nestel, P. J. (1964). Relationship between plasma triglycerides and removal of chylomicrons. Fournal of Clinical Investigation, 43, 943. 
Ozonoff, M. B., and Clemett, A. R. (1967). Progressive osteolysis in progeria. American fournal of Roentgenology, Radium Therapy and Nuclear Medicine, 100, 75.

Rosenthal, I. M., Bronstein, I. P., Dallenbach, F. D., Pruzansky, S., and Rosenwald, A. K. (1956). Progeria: report of a case with cephalometric roentgenograms and abnormally high concentrations of lipoproteins in the serum. Pediatrics, 18, 565.

Sackett, G. E. (1925). Modification of Bloor's method for the determination of cholesterol in whole blood or serum. Fournal of Biological Chemistry, 64, 203.

Salt, H. B., and Wolff, O. H. (1957). The applications of serum lipoprotein electrophoresis in paediatric practice. Archives of Disease in Childhood, 32, 404.
Talbot, N. B., Butler, A. M., Pratt, E. L., MacLachlan, E. A., and Tannheimer, J. (1945). Progeria: clinical, metabolic and pathologic studies on a patient. American fournal of Diseases of Children, 69, 267.

Thomson, J., and Forfar, J. O. (1950). Progeria (HutchinsonGilford syndrome): report of a case and review of the literature. Archives of Disease in Childhood, 25, 224.

Villee, D. B., Nichols, G., Jr., and Talbot, N. B. (1969). Metabolic studies in two boys with classical progeria. Pediatrics, 43, 207.

Correspondence to Dr. B. G. P. Macnamara, George Eliot Hospital, College Street, Nuneaton. 